\title{
Bilateral variations of the great saphenous vein
}

\author{
Ali ZEYBEK (D), Mazhar OZKAN (D), Meltem ALPAY \\ Department of Anatomy, Faculty of Medicine, Tekirdag Namik Kemal University, Tekirdag, Turkey.
}

Corresponding Author: Ali ZEYBEK

E-mail: alize05@yahoo.com

Submitted: 11.01.2021 Accepted: 17.03.2021

\begin{abstract}
The great saphenous vein is the longest in the human body and has been one of the most preferred autologous tissue in bypass surgery. It is affected by the life conditions causing pathological dilatations called varices. We observed bilaterally duplicated great saphenous vein in both lower limbs of an elderly male human cadaver during our routine dissection for undergraduate anatomy education. After a detailed inspection of the veins at both sides, we measured and illustrated the variant branches. In this case report, we presented bilaterally duplicated great saphenous veins, accompanied by an accessory saphenous vein. To the best of our knowledge, there are no such variations reported in the literature so far. We think that recognizing this and such variations before surgery will increase success. Keywords: Great saphenous vein, Bilateral variation, Cadaver
\end{abstract}

\section{INTRODUCTION}

The great saphenous vein (GSV) starts from the medial marginal vein of the dorsal venous arch of the foot and ascends to the lower extremity's medial side. It drains into the common femoral vein below the inguinal ligament [1]. GSV is the longest superficial vein in the human body used as an autologous tissue in coronary artery bypass surgery due to its structure rich in elastic and muscular fibers [2]. Conversely, the GSV and its branches are prone to venous insufficiency resulting in varicose veins, a condition treated with high ligation, stripping, or radiofrequency thermoablation. Thus, knowledge of the morphological features and concomitant structures (especially saphenous nerve) of the GSV is crucial.

In our department, routine dissections performed in a 60 -yearold male human cadaver revealed GSV variations in both lower extremities.

\section{CASE REPORT}

Herein, we report GSV variations in both lower extremities of a 60 -year-old male human cadaver during routine dissection for the medical undergraduate students. In the right lower extremity, at $145 \mathrm{~mm}$ above the medial malleolus, a 540-mmlong GSV was divided into a thin medial (with a diameter of 1 $\mathrm{mm}$ in the leg and $2 \mathrm{~mm}$ in the thigh) and a thick lateral (with a diameter of $3 \mathrm{~mm}$ in the leg and $6 \mathrm{~mm}$ in the thigh) branches, reunited and drained into a common femoral vein $(15.2 \mathrm{~cm}$ long and $7 \mathrm{~mm}$ thick). An accessory saphenous vein (ASV) was observed in the thigh region (Fig 1). In the left lower extremity, at $140 \mathrm{~mm}$ above the medial malleolus, a 112-mm-long GSV was divided into a thick medial (with a diameter of $3 \mathrm{~mm}$ ) and a thin lateral (with a diameter of $2 \mathrm{~mm}$ ) branch. These adjacent branches ascended proximally along $88 \mathrm{~mm}$ and at $485 \mathrm{~mm}$ in length, were divided into thick medial (with a diameter of $3.5 \mathrm{~mm}$ ) and thin lateral (with a diameter of $3 \mathrm{~mm}$ ) branches, similar to the leg region, and finally drained into the femoral vein separately (Fig 2).

How to cite this article: Zeybek A, Ozkan M, Alpay M. Bilateral variations of the great saphenous vein. Marmara Med J 2021; 34(2):219-221. doi: 10.5472/ marumj. 945178 


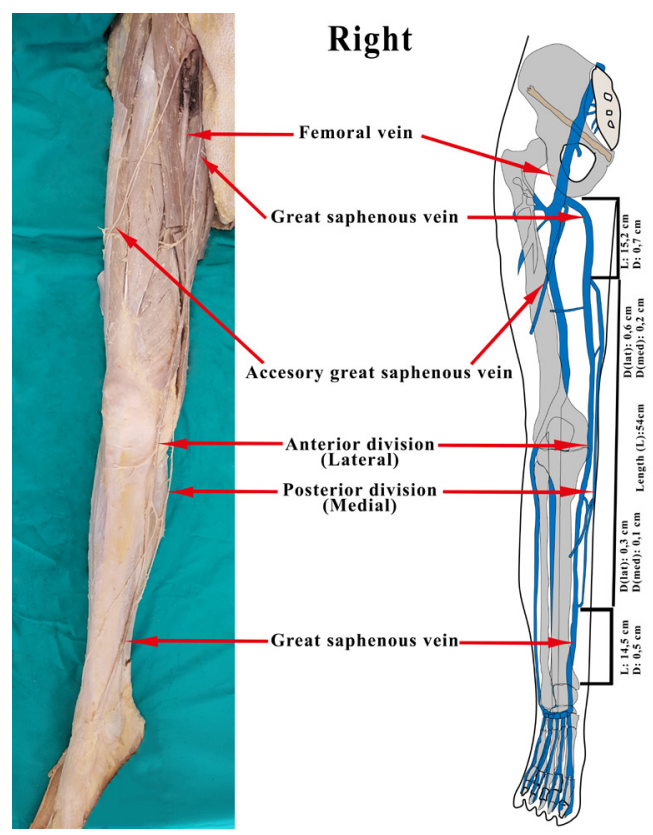

Figure 1. A photograph and an illustration of the variation of the right great saphenous vein and the accessory saphenous vein on the right thigh. $D$, diameter; $D$ (lat), diameter of the lateral division; $D($ med), diameter of the medial division; $L$, length.

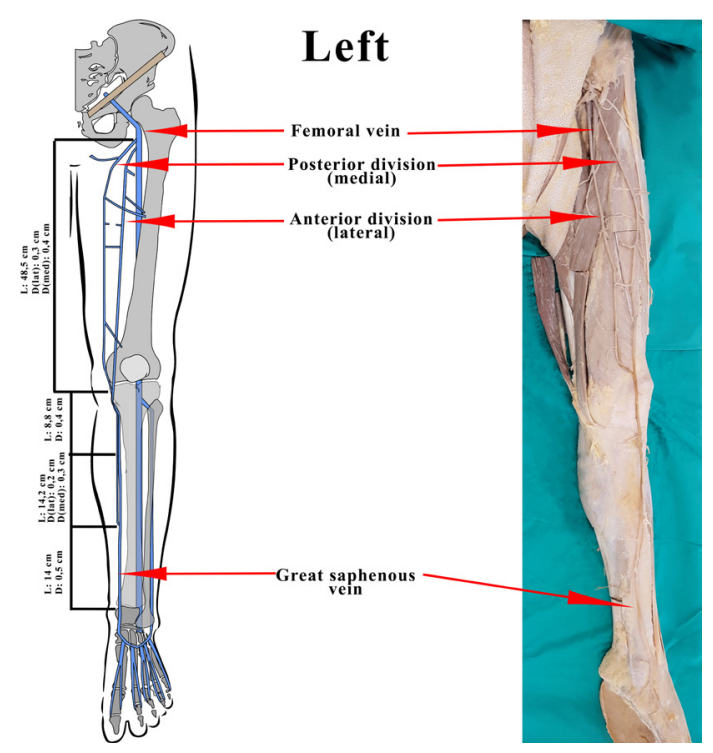

Figure 2. A photograph and an illustration of the variation of the left great saphenous vein. $D$, diameter; $D($ lat $)$, diameter of the lateral division; $D$ (med), diameter of the medial division; L, length.

\section{DISCUSSION}

The frequency of variations observed in venous anatomy causes difficulties in nomenclature and teaching. GSV duplication has been reported unilaterally [3], complete [4], or segmental [5]. However, as far as we know, bilateral duplication has not been reported in the literature yet [6]. They are also unique in that they differ from each other according to how they drain into the common femoral vein.

On the other hand, to the best of our knowledge, ASV variation in the right lower extremity has not been reported so far. In a recent study, it has been reported that accessory veins in the lower extremity negatively affect superficial venous thrombus treatments [7]. For this reason, defining this variation seen in our case may be useful in thrombophlebitis treatment.

Variations in this structure are important in clinical conditions such as harvesting as a graft for coronary bypass surgery [8]. The larger the graft's diameter, the more successful the surgical procedure [9]; accordingly, variations with a bifurcation of narrow vessels have been associated with poor outcome of surgery [10]. Besides, duplicated GSV cases have been reported to cause recurrent varicosities [11].

In conclusion, awareness of this variation in surgical and medical treatment processes will reduce its potential negative effects.

Conflict of interest: The authors have no potential conflicts to declare

Funding: The authors received no financial support for the research, authorship, and/or publication of this article.

Human rights: All procedures were performed in accordance with basic ethical principles.

\section{REFERENCES}

[1] İmamoğlu H, Erdoğan N, Doğan S, Kahriman G. A rare anatomical variation of the great saphenous vein course. Cardiovasc Intervent Radiol 2017;40:1653-4, doi: 10.1007/ s00270.017.1628-y

[2] Barner HB, Farkas EA. Conduits for coronary bypass: vein grafts. Korean J Thorac Cardiovasc Surg 2012;45:275, doi: 10.5090/kjtcs.2012.45.5.275.

[3] Özyurt B, Uysal M, Taş U, Çiçek M. Duplication of vena saphena magna: A variation in a male cadaver. Gaziosmanpaşa Üniversitesi Tip Fakültesi Dergisi 2013;5:164-71, https:// dergipark.org.tr/en/pub/gutfd/issue/34276/378807

[4] Packiriswamy V, Nayak SB. Saphenous Ladder formed by almost completely duplicated great saphenous vein. Kathmandu University Medical Journal (KUMJ). 2020;18:99101.

[5] Ricci S, Caggiati A. Does a double long saphenous vein exist? Phlebology 1999;14:59-64, doi:10.1177/026.835.559901400205

[6] Cavezzi A, Labropoulos N, Partsch H, et al. Duplex ultrasound investigation of the veins in chronic venous disease of the lower limbs-UIP Consensus Document. Part II. Anatomy. Eur J Vasc Endovascu Surg 2006;31:288-99, doi: 10.1016/j. ejvs.2005.07.020 
[7] Schul MW, Vayuvegula S, Keaton TJ. The clinical relevance of anterior accessory great saphenous vein reflux. J Vasc Surg Venous Lymphat Disord 2020;8:1014-20, doi: 10.1016/j. jvsv.2020.02.010

[8] Cheung-Flynn J, Song J, Voskresensky I, et al. Limiting injury during saphenous vein graft preparation for coronary arterial bypass prevents metabolic decompensation. Sci Rep 2017;7:14179. doi:10.1038/s41598.017.13819-w

[9] Zachrisson $H$, Lindenberger $M$, Hallman D, Ekman M, Neider D, Länne T. Diameter and compliance of the greater saphenous vein-effect of age and nitroglycerine. Clin
Physiol Funct Imaging 2011;31:300-6. doi: 10.1111/j.1475097X.2011.01016.X

[10] Motwani R, Jain P. Duplication of great saphenous vein-Anatomical description and its clinical implications. Int J Biol Med Res 2013;4:3372-4, doi: 10.1.1.398.3693\&rep=rep1\&type $=$ pdf

[11] Schanzer A, Hevelone N, Owens CD, et al. Technical factors affecting autogenous vein graft failure: observations from a large multicenter trial. J Vasc Surg 2007;46:1180-90, doi: 10.1016/j.jvs.2007.08.033. 